\section{P-015 INFLUENCE OF CORE INFARCT VOLUME AND PATIENT AGE ON CLINICAL OUTCOME IN ENDOVASCULAR TREATMENT OF LARGE VESSEL OCCLUSION FOR ACUTE STROKE}

${ }^{1} \mathrm{~N}$ Telischak, ${ }^{1} \mathrm{~A}$ Faisal, ${ }^{1} \mathrm{~J}$ Wong, ${ }^{1} \mathrm{~A}$ Moraff, ${ }^{1} \mathrm{H}$ Do, ${ }^{1} \mathrm{R}$ Dodd, ${ }^{1} \mathrm{~J}$ Heit, ${ }^{2} \mathrm{M}$ Mlynash, ${ }^{2} \mathrm{M}$ Lansberg, ${ }^{2} \mathrm{G}$ Albers, ${ }^{1} \mathrm{M}$ Marks. ${ }^{1}$ Interventional Neuroradiology, Stanford University, Stanford, CA; ${ }^{2}$ Neurology, Stanford University, Stanford, CA

10.1136/neurintsurg-2016-012589.57

Introduction Endovascular therapy of acute ischemic stroke is the standard of care, but controversy exists regarding how the size of the pre-treatment infarction and patient age should influence patient selection for endovascular treatment. Magnetic resonance imaging (MRI) with diffusion-weighted imaging (DWI) or computed tomography perfusion (CTP) can estimate the pre-treatment infarct volume (core). Studies have examined the interplay between core and patient age, however to date sufficient data do not exist to guide decision making in octogenarians with stroke. We undertook this study to examine the influence of infarct core and age on clinical outcome.

Methods Patients treated between July 2008 and September 2011 from a previously reported study (DEFUSE2) and all patients treated at our institution between September 2012 and June 2015 who underwent endovascular therapy for anterior circulation stroke using available devices were included. Patient demographic data, stroke risk factors, and treatment details were recorded. Core infarct volumes were determined with either DWI MRI or CBF CTP. The primary outcome was good functional outcome of modified Rankin score 0-2 at 90 days; a secondary measure was TICI $2 \mathrm{~B} / 3$ reperfusion. ROC analysis was performed for lesion size and age to determine values above which there was $<10 \%$ chance of a good clinical outcome.

Results 154 patients (mean 69 years (SD 14), 85 (55\%) female) met inclusion criteria and had clinical follow-up. Forty-two $(27 \%)$ were $\geq 80$ years. Median time to imaging was 4.5 hours (IQR 2.9-6.7). 136 patients had pre-treatment MRI and 18 had CTP. TICI $2 \mathrm{~B} / 3$ reperfusion was achieved in 91 patients (59\%). In univariate analysis, TICI $2 \mathrm{~B} / 3$ reperfusion $(\mathrm{p}<0.001)$, core volume $(\mathrm{p}=0.02)$, age $(\mathrm{p}=0.001)$, and baseline NIHSS $(\mathrm{p}<0.001)$ were significant predictors for good outcome. An ROC analysis for core size determined a volume of $<45 \mathrm{~mL}$ yielded a PPV of at least $10 \%$ for good outcome. 44/82 (54\%) of patients with $<45$ $\mathrm{ml}$ core and TICI $2 \mathrm{~b} / 3$ reperfusion had a good outcome, while $1 / 9(11.1 \%)$ with $>45 \mathrm{ml}$ core and TICI $2 \mathrm{~b} / 3$ had a good outcome $(p=0.030)$. This threshold remained an independent predictor when adjusted for age, NIHSS and TICI 2 $\mathrm{B} / 3$ reperfusion $(\mathrm{OR}=6.7,95 \%$ CI $1.2-36)$. In ROC analysis for age, $<83$ years best differentiated the groups with at least $10 \%$ chance of good outcome. An ROC analysis in patients $>80$ years showed a core of $\leq 16 \mathrm{~mL}$ yielded positive predictive value of $10 \%$ or better for a good outcome, but the differences in the rates of good outcome at this threshold were not significant.

Conclusion This study found TICI 2 B/3 reperfusion, core volume, age, and baseline NIHSS were independent predictors for good outcome. ROC analysis demonstrated a core infarct volume of $<45 \mathrm{ml}$ had a PPV of at least $10 \%$ of yielding a good outcome. For patients $>80$ years the ROC analysis demonstrated that a core infarct volume of $<16 \mathrm{ml}$ had a PPV of $10 \%$ or better of yielding a good outcome, suggesting that older patients tolerate a smaller core. However, the current study was underpowered to identify the significance of this threshold.

Disclosures N. Telischak: None. A. Faisal: None. J. Wong: None. A. Moraff: None. H. Do: None. R. Dodd: None. J. Heit: None. M. Mlynash: None. M. Lansberg: None. G. Albers: None. M. Marks: None.

\section{P-016 SUCCESSFUL FLOW DIVERSION OF CEREBRAL ANEURYSMS IN PLAVIX HYPORESPONDERS (PRU $\geq 200$ ): AN ARGUMENT FOR ANTIPLATELET MONOTHERAPY?}

${ }^{1} \mathrm{G}$ Colby, ${ }^{2} \mathrm{~L}$ Lin, ${ }^{1} \mathrm{D}$ Lubelski, 'M Bender, ${ }^{1} \mathrm{R} X \mathrm{X},{ }^{1} \mathrm{~B}$ Jiang, ${ }^{1} \mathrm{~J}$ Huang, ${ }^{1} \mathrm{R}$ Tamargo, ${ }^{1} \mathrm{~A}$ Coon. ${ }^{1}$ Neurosurgery, Johns Hopkins, Baltimore, MD; ${ }^{2}$ Neurosurgery, UC Irvine, Costa Mesa, $C A$

\subsection{6/neurintsurg-2016-012589.58}

Introduction Endovascular aneurysm treatment by flow diversion has classically relied on dual anti-platelet therapy with Aspirin and Plavix to reduce thrombotic complications. The heterogenous Plavix response of patients has made P2Y12 testing increasingly popular. Plavix hyporesponders (defined as PRU $\geq 200$ ) are often re-dosed with Plavix or switched to alternate anti-platelet regimens. However, little clinical validation exists for these practices, and they might actually increase risks of hemorrhagic complications. We sought to evaluate periprocedural outcomes following flow diversion in patients maintained on standard Aspirin and Plavix regimens with PRU $\geq 200$.

Methods A single-center prospectively collected aneurysm database was reviewed for adult patients on standard dual antiplatelet regimens (Aspirin $325 \mathrm{mg}+$ Plavix $75 \mathrm{mg}$ daily) who underwent endovascular embolization of ICA and proximal ACA/Acom aneurysms with the Pipeline Embolization Device (PED). Patients with pre-embolization P2Y12 testing and PRU level $\geq 200$ were included.

Results 49 patients (mean age 56,74\% women) met inclusion criteria. Forty-seven (96\%) patients had a single aneurysm treated, and 2 (4\%) had 2 aneurysms treated; 84\% of aneurysms were on the ICA and 16\% on the ACA (Acom and A12). Aneurysm size ranged from 2-28 mm. PED length ranged from 10-35 mm. Pre-procedure PRU levels ranged from 200 to 361. RePro was administered in 5/49 (10\%) cases, with platelet plug visualized in $4 / 49$ cases $(8 \%)$. Four patients $(8 \%)$ had transient neurological deficits (resolved completely during hospital stay), with only 1 of these requiring ReoPro during the procedure. No patients had major or minor permanent strokes, and no patients had hemorrhagic complications.

Conclusions Hyporesponse to Plavix (PRU $\geq 200$ ) is not a contraindication to aneurysm treatment with the PED in patients on a standard dual antiplatelet regimen of Aspirin $325 \mathrm{mg}$ and Plavix $75 \mathrm{mg}$ daily. These data suggest a diminutive role of Plavix in preventing thrombotic complications during these procedures.

Disclosures G. Colby: 1; C; Stryker, Medtronic. 2; C; Microvention. L. Lin: 1; C; Stryker. D. Lubelski: None. M. Bender: None. R. Xu: None. B. Jiang: None. J. Huang: None. R. Tamargo: None. A. Coon: 1; C; Sequent. 2; C; Stryker, Medtronic, Microvention, Sequent. 